\title{
УДК 635.64:632.38:632.15 https://doi.org/10.53040/gppb7.2021.25 \\ ОСОБЕННОСТИ МУЖСКОГО ГАМЕТОФИТА ТОМАТА В УСЛОВИЯХ ВИРУСНОГО ПАТОГЕНЕЗА И ВОДНОГО ДЕФИЦИТА
}

\author{
Салтанович Т.И., Анточ Л.П., Дончилэ А.Н. \\ Институт генетики, физиологии и защиты растений, Кишинэу, Республика Молдова \\ e-mail: tatiana.saltanovici@igfpp.md
}

\begin{abstract}
On the example of $F_{1}$ hybrid combinations and tomato varieties, the possibility of the assessing method for pollen selection on the responses of male gametophytes under conditions of viral pathogenesis and drought has been shown. It was found the action of factors on the pollen viability and on the rate of pollen tubes growth, leading to the manifestation of differential reactions. The viruses are the main sources of variability of the pollen functional traits, while the effect of water deficit and genotype are considerably weaker. Genotypes that combine the high viability of pollen with the ability to form longer pollen tubes under the complementary action of viruses and water deficit have been identified, suggesting the prospect of these genotypes using in further breeding studies.
\end{abstract}

Key words: tomato, virus, pollen, viability, variability, resistance, selection.

\section{Введение}

Среди абиотических стрессов, влияющих на растения, засуха является одним из наиболее лимитирующих, так как напрямую влияет на завязываемость плодов. Известно, что довольно часто периоды недостатка влаги совпадают с репродуктивной фазой жизненного цикла, когда растения особенно чувствительны к этому фактору [1]. Даже у такой засухоустойчивой культуры как сорго, действие водного стресса на вегетативной стадии снижает урожай более чем на $36 \%$, тогда как на репродуктивных этапах продуктивность уменьшается на 55\% [2]. Реагируют на недостаток влаги и генотипы томата, показано, что несмотря на то, что реакция генотипов на сильную засуху дифференцирована, в большинстве случаев, ее действие уменьшает количество бутонов, цветков и плодов, что в итоге негативно сказывается на продуктивности растений [3]. Известно, что пыльцевые зерна тоже реагируют на водный дефицит, так, если при оптимальных условиях содержание воды составляет около $60 \%$ их веса, то действие недостатка влаги может привести к снижению этого показателя примерно на 30\% [4].

В процессе селекции, довольно часто, растения на разных этапах вегетации, в том числе репродуктивных, оказываются под влиянием комплексного действия абиотических и биотических факторов, что оказывает значительное влияние на взаимодействие растений с патогенами. Следует отметить, что в литературе информация о реакции растений, подвергающихся одновременно абиотическим и биотическим воздействиям, ограничена и носит неоднозначный характер. Сообщается, что в условиях совместного действия факторов ответная реакция растений определяется типом абиотического стресса и патогена [5]. В таких условиях действие абиотического фактора вызывает положительное или отрицательное взаимодействие растений и патогенов, что может усиливать или уменьшать симптомы проявления заболевания и его влияние на растение. Известны случаи, когда при одновременном действии водного дефицита и вирусов у ряда растений хозяев отмечено замедление проявления симтомов засухи, т.е. на фоне вирусного патогенеза авторы наблюдали повышение устойчивости к абиотическому стрессу [6]. В некоторых исследованиях, например, на растениях свеклы, при совместном действии вирусов и недостатка влаги вообще не обнаружено эффекта взаимодействия между 2-мя стрессами. Использование на арабидопсисе многофакторной тестовой системы, сочетающей действие 3-х факторов (температура, засуха и вирус), показало, что экспрессия генов в условиях многофакторного стресса не может быть прогнозирована как результат отдельного воздействия каждого из факторов [5].

Таким образом, в условиях комплексного действия абиотических факторов и вирусов могут наблюдаться различные типы взаимодействий, зависящие от типа абиотического фактора и вируca, а также растения хозяина. Однако, сведений о реакции мужского гаметофита растений на мно- 
гофакторные стрессовые воздействия мы на обнаружили, в этой связи цель проведенных исследований состояла в изучении особенностей мужского гаметофита томата в условиях комплементарного действия вирусных патогенов и водного дефицита.

\section{Материалы и методы}

$\mathrm{B}$ качестве объекта исследований использовали гибридные комбинации $\mathrm{F}_{1}$ и сорта томата. Эксперименты проводили в условиях теплицы и в лаборатории. Растения выращивали рендомизированно по общепринятой для томатов методике, в фазе 4-5 листьев проводили их механическую инокуляцию вирусом табачной мозаики (BTM) или вирусом аспермии томата (BAT).

Для определения качества пыльцы собирали цветки с контрольных и инфицированных растений, отделяли и подсушивали пыльники, выделяли пыльцу и высевали ее на искусственную питательную среду. Для моделирования условий водного дефицита при культивировании пыльцы питательную среду дополняли селективной концентрацией сахарозы. Культивиование пыльцы осуществляли в термостате при оптимальном температурном режиме $26-28^{\circ} \mathrm{C}$ в течение 3 -х часов. Анализировали препараты под микроскопом, определяли жизнеспособность пыльцы (ЖП) и длину пыльцевых трубок (ПТ) в контрольном и опытных вариантах, а также вычисляли соотношение этих показателей. Статистическую обработку полученных результатов проводили с использованием программ Statgraphics Plus 5.0 и Exel 2013.

\section{Результаты и обсуждение}

Результаты проведенных экспериментов показали, что совместное влияние ВАТ или ВТМ и недостатка влаги снижало жизнеспособность пыльцы изученных генотипов в среднем на 23,6 ...31,2\%, при этом наиболее сильная реакция отмечена у сортов томата (снижение ЖП составляло $28,0 \ldots 31,2 \%)$, тогда как у гибридов этот показатель был ниже $(19,4 \ldots 29,0 \%)$. Следует отметить, что в этих же условиях формировались и более короткие пыльцевые трубки, длина которых в среднем по всем генотипам по сравнению с контрольным вариантом была меньше в 2,2 и 2,6 раза (ВАТ, ВТМ соответственно).

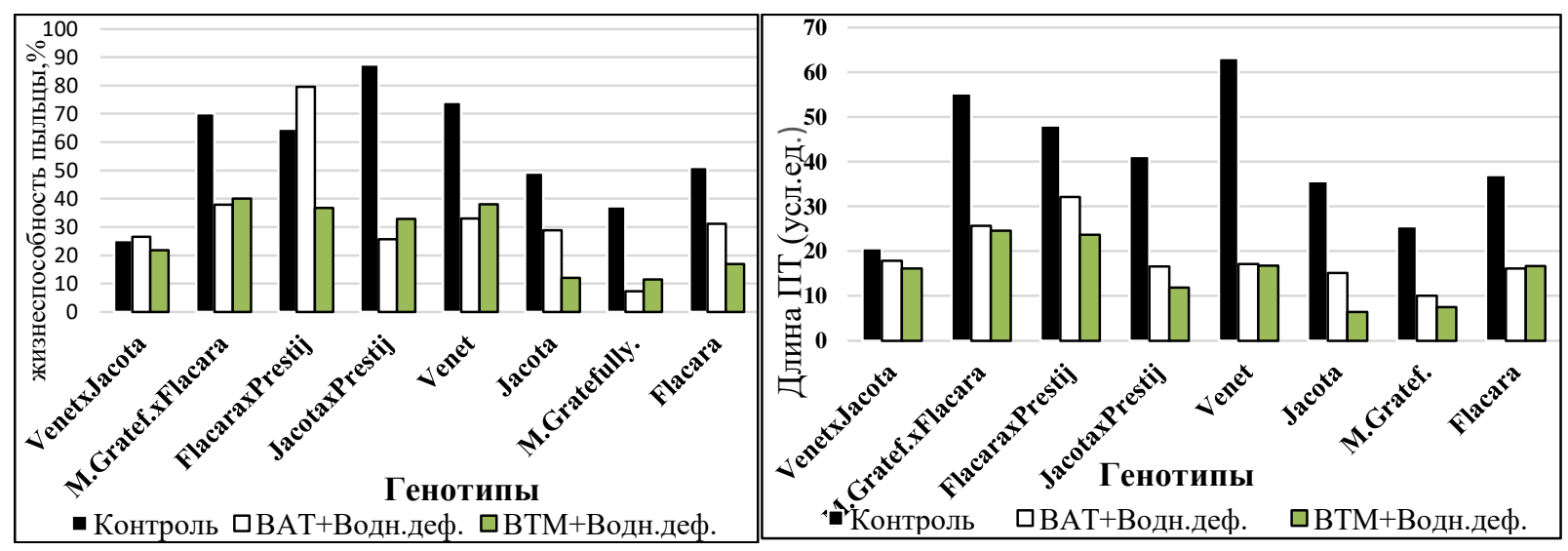

Рис. Влияние вирусов и водного дефицита на признаки мужского гаметофита томата.

Выявлено, что по длине пыльцевых трубок наиболее сильные различия по отношению к контролю (в 3,0 и 3,4 раза) также проявились у сортов томата, тогда в гибридных популяциях этот признак уменьшался гораздо слабее (в 1,8 ..2,2 раза). Таким образом, в условиях совместного воздействия факторов скорость роста пыльцевых трубок замедляется, что в итоге приводит к уменьшению их длины по сравнению с контролем.

В тоже время следует отметить, что реакция генотипов на многофакторное стрессовое воздействие была дифференцированной (рис.). Среди изученных генотипов особенно чувствительными как по жизнеспособности пыльцы, так и по длине пыльцевых трубок, оказались пыльцевые зерна гибридной комбинаций $\mathrm{F}_{1}$ Jacota x Prestij и сорта Venet. 
Для выявления основных источников обнаруженной вариабельности признаков проведена обработка полученных результатов методом многофакторного дисперсионного анализа. Установлено, что во всех вариантах опыта действие генотипа, вирусов, водного дефицита, а также различные их взаимодействия достоверно влияют на изменчивость признаков пыльцы. Так, анализ состава спектра изменчивости жизнеспособности пыльцы показал, что 90,4\% вариабельности достоверно $(\mathrm{P}<0,001)$ детерминировано действием вируса, водного дефицита и генотипа. При этом более половины изменчивости этого признака вызывает вирусная инфекция, тогда как сила влияния водного дефицита была вдвое слабее (табл.1).

Как показали полученные результаты, основными факторами вариабельности размеров пыльцевых трубок также были вирусы, недостаток влаги и генотип, сила их совместного действия составляла 91,4\%. При этом около 65\% выявленной изменчивости определял ВТМ, тогда как действие недостатка влаги было более слабым (в 3,5 раза). Влияние ВАТ было еще более сильно изменяло размеры ПТ, определяя $73,1 \%$ их изменчивости, действие генотипа и водного дефицита были более слабыми (табл.1).

Таблица 1 Источники изменчивости признаков мужского гаметофита

\begin{tabular}{|c|c|c|c|c|c|c|}
\hline \multirow{2}{*}{$\begin{array}{c}\text { Источники } \\
\text { изменчивости }\end{array}$} & \multicolumn{3}{|c|}{ Жизнеспособность пыльцы } & \multicolumn{3}{|c|}{ Длина ПТ } \\
\hline & $\begin{array}{c}\text { Степеньс } \\
\text { вободы }\end{array}$ & $\begin{array}{l}\text { Сумма квадра- } \\
\text { тов эффектов }\end{array}$ & $\begin{array}{c}\text { Доля } \\
\text { влияния, } \\
\%\end{array}$ & $\begin{array}{l}\text { Степень } \\
\text { свободы }\end{array}$ & $\begin{array}{c}\text { Сумма } \\
\text { квадратов эффек- } \\
\text { тов }\end{array}$ & $\begin{array}{c}\text { Доля } \\
\text { влияния, } \\
\%\end{array}$ \\
\hline \multicolumn{7}{|c|}{ ВТМ+Водный дефицит } \\
\hline Генотип & 7 & 14282 & 13,8 & 7 & 6697 & 9,23 \\
\hline BTM & 1 & 8471 & 54,0 & 1 & 6648 & 64,2 \\
\hline Водный дефицит & 1 & 3550 & 22,6 & 1 & 1859 & 18,0 \\
\hline Взаимодействие факторов & 22 & 9167 & 9,6 & 22 & 4004 & 8,6 \\
\hline Случайные эффекты & 64 & 178 & 1,9 & 71 & 1048 & \\
\hline \multicolumn{7}{|c|}{ ВАТ+Водный дефицит } \\
\hline Генотип & 7 & 13392 & 10,7 & 7 & 4712 & 8,10 \\
\hline BAT & 1 & 13706 & 76,9 & 1 & 6113 & 73,1 \\
\hline Водный дефицит & 1 & 1,48 & 0,01 & 1 & 466 & 5,2 \\
\hline Взаимодействие факторов & 22 & 11819 & 12,4 & 22 & 4010 & 12,7 \\
\hline Случайные эффекты & 64 & 169,8 & & 71 & 1930 & 0,3 \\
\hline
\end{tabular}

* - различия достоверны при $\mathrm{P}<0,001$

В условиях совместного действия ВАТ и водного дефицита выявленная вариабельность как по жизнеспособности пыльцы, так и по длине трубок были детерминированы действием вируса, недостатка влаги и генотипа, при этом основным источником изменчивости каждого из признаков был ВАТ (табл. 1).

На основе обобщения полученных результатов установлено, что среди изученных гибридных комбинаций выделяются гибриды $\mathrm{F}_{1}$ M.Gratefully x Flacara, Flacara x Prestij, а также сорта Venet и Flacara, которые в условиях многофакторных стрессовых фонов сочетали высокие показатели жизнеспособности пыльцы со способностью формировать пыльцевые трубки большей длины (табл. 2). Таким образом, в условиях комплексного действия вирусов и водного дефицита наблюдаются значительные различия по качеству мужского гаметофита, позволяющие дифференцировать генотипы по их реакции на стресс. 
Таблица 2 Характеристика мужского гаметофита томата в условиях стрессовых фонов

\begin{tabular}{|c|c|c|c|c|}
\hline \multirow[b]{2}{*}{ Генотип } & \multicolumn{2}{|c|}{ Жизнеспособность пыльцы,\% } & \multicolumn{2}{|c|}{ Длина ПТ, усл.ед. } \\
\hline & $\begin{array}{c}\text { ВТМ+водный } \\
\text { дефицит }\end{array}$ & ВАТ+водный дефицит & $\begin{array}{c}\text { ВТМ+водный } \\
\text { дефицит }\end{array}$ & $\begin{array}{c}\text { ВАТ+водный } \\
\text { дефицит }\end{array}$ \\
\hline$F_{1}$ Venet $x$ Jacota & 25,4 & 26,2 & 22,9 & 18,4 \\
\hline $\mathrm{F}_{1}$ M.Gratefully x Flacara & 53,8 & 44,8 & 37,1 & 34,8 \\
\hline$F_{1}$ Flacara $x$ Prestij & 49,8 & 61,8 & 31,3 & 33,1 \\
\hline$F_{1}$ Jacota $x$ Prestij & 50,1 & 48,2 & 26,1 & 26,7 \\
\hline c.Venet & 51,0 & 56,7 & 36,7 & 34,3 \\
\hline c. Jacota & 28,8 & 40,3 & 15,4 & 26,6 \\
\hline c. M.Gratefully & 21,6 & 27,3 & 12,9 & 14,3 \\
\hline c. Flacara & 40,2 & 39,9 & 27,0 & 24,4 \\
\hline $\mathrm{HCP}_{0.5}$ & $\mathbf{1 , 5 3}$ & $\mathbf{1 , 5 0}$ & 3,54 & 4,8 \\
\hline
\end{tabular}

\section{Выводы}

Действие вирусных патогенов и водного дефицита может ослаблять или усиливать защитные реакции растений, приводя на уровне мужского гаметофита к возникновению стимуляционного, ингибирующего или нейтрального эффектов.

В условиях комплементарного действия вирусов (ВТМ или ВАТ) и водного дефицита главными источниками изменчивости жизнеспособности пыльцы и длины пыльцевых трубок являются вирусы, детерминирующие 54,0 ..76,9\% вариабельности этих признаков.

Мужской гаметофит гибридов $F_{1}$ (M.Gratefully x Flacara, Flacara x Prestij, Jacota x Prestij) и сортов (Venet и Flacara) при совместном действии вирусов (BMT или BAT) и водного дефицита сочетает высокую жизнеспособность пыльцы со способностью формировать пыльцевые трубки большей длины, что предполагает перспективу использования этих генотипов в дальнейших исследованиях.

Исследования проведены в рамках проекта Государственной Программы 20.80009.7007.04 «Биотехнологии и генетические способы выявления, сохранения и использования агробиоразнообразия», финансируемой Национальным Агентством по Исследованиям и Развитию.

\section{Литература}

1. YU, J., JIANG, M., GUO, C. Crop pollen development under drought: From the phenotype to the mechanism. In: Int. J. Mol. Sci. 2019. Vol. 20 (7), p. 1550.

2. ASSEFA, Y., SCOTT, A. Staggenborg et al. Grain sorghum water requirement and responses to drought stress: A Review. In: Plant Management Network. 2010. Vol.9, p. 1-11.

3. SHOWEMIMO, F., OLAREWAJU, J., BUAH, J. et al. Genetic estimates of water stress in tomato (Lycopersicum esculentum). In: International Journal of Plant Breeding and Genetics. 2007. Vol. 1, p. 18-23.

4. PACINI, E., DOLFERUS, R. Pollen dewvelopmental arrest: maintaining pollen fertility in a world with a changing climate. In: Front.Plant Sci.2019. Vol. 10, p. 1-15.

5. PRASCH, C., SONNEWALD, U. Simultaneous application of heat, drought and virus to Arabidopsis plants reveals significant shifts in signaling networks. In: Plant Physiology. 2013. Vol. 162, p. 1849-1866.

6. HOSSEINI, S., YAGHUB, G., KHAYYAT, Z. Effects of cucumber mosaic virus infection and drought tolerance of tomato plants under greenhouse conditions: Preliminary results. In: Journal of Berry Research. 2018. Vol. 8(2), p. $129-136$. 